\title{
AVALIAÇÃO DA ROTULAGEM DE ALIMENTOS DA CULINÁRIA JAPONESA
}

\section{EVALUATION OF FOOD LABELS ON JAPANESE CUISINE}

\author{
Edeli Simioni de Abreu ${ }^{1}$ \\ Gabriela Yoshizaki \\ Anita Akiko Takahashi ${ }^{3}$
}

RESUMO: A Agência de Vigilância Sanitária tornou obrigatória a rotulagem nutricional, de alimentos embalados, pelas resoluções $R D C$ no 39, no 40 e $n^{\circ} 360$, pois a informação sobre a composição nutricional dos alimentos comercializados é muito importante na contribuição para a saúde dos consumidores. Assim, o objetivo deste estudo foi avaliar os conteúdos da informação nutricional apresentados nos rótulos de alimentos da culinária japonesa, disponíveis em estabelecimentos comerciais de um bairro oriental de São Paulo. Foram escolhidos quatro alimentos, conhecidos da culinária japonesa, comercializados em bairro oriental de São Paulo. Os alimentos escolhidos foram: tikuwa, manju, tofu e missô, totalizando seis amostras. As informações contidas nas embalagens desses alimentos foram analisadas de forma indireta, utilizando-se tabela específica de composição nutricional de alimentos da culinária japonesa, desenvolvida por pesquisadores da Universidade de São Paulo, de acordo com as resoluções da ANVISA RDC $n \circ 39 ; R D C n^{\circ} 40$ e RDC $n^{\circ} 360$. Os resultados demonstraram que $100 \%$ dos rótulos analisados não estavam em conformidade com a legislação vigente. $O$ intervalo de variação foi de 10 a 93\%, para proteínas, de 17 a 157\%, para carboidratos, e de 10 a 136\%, para gorduras totais, que, por se tratar de nutrientes energéticos, acarretam grande variação ao valor calórico dos produtos. Pode-se concluir que há uma disparidade muito grande entre o que esta no rótulo e o encontrado nas tabelas de composição de alimento.

Palavras-chave: comida japonesa; rotulagem de alimentos; informação nutricional.

ABSTRACT: The Brazilian Agency of Health Oversight (ANVISA) mandated nutrition labeling on packaged foods in RDC resolutions number 39, 40, and 360, because nutritional information about the composition of food is important for consumer's health. The objective of this study was to evaluate the nutritional contents of the information issued on the labels of Japanese cuisine available in commercial establishments of a Japanese community in São Paulo. The four Japanese foods sold in São Paulo that were chosen included tikuwa, manju, tofu, and miso, totaling six samples. The nutritional contents of food packaging were analyzed in an indirect way, using conventional tables for food's nutritional composition of Japanese food developed by researchers at São Paulo University (USP) in accordance with the resolutions of ANVISA RDC $n^{\circ} 39,40$, and 360. The results demonstrated that $100 \%$ of the labels analyzed were not in accordance with the resolution of ANVISA RDC number 360 . The range was from 10 to $93 \%$ for proteins, 17 to $157 \%$ for carbohydrates, and 110 to $136 \%$ for total fat, which in the case of energy, leads to a wide variation in nutrients for the energetic value of products. Therefore, there is a large disparity between what labels state and what is found in food composition tables.

Keywords: Japanese food; food labeling; nutritional information.

\footnotetext{
1 Doutora em Saúde Pública pela Universidade de São Paulo - USP. Professora Adjunto I do curso de Nutrição da Universidade Presbiteriana Mackenzie - UPM. E-mail: edelisabreu@gmail.com.

${ }^{2}$ Bacharel em Farmácia - UPM. E-mail: bii_86@hotmail.com.

${ }^{3}$ Bacharel em Nutrição - UPM. E-mail: takah_anita@yahoo.com.br.
} 


\section{INTRODUÇÃO}

A história dos restaurantes japoneses, na cidade de São Paulo, começou na década de 1910, dentro de pensões. A partir dos anos 20, esses estabelecimentos já se concentravam em torno da Rua Conde de Sarzedas (Liberdade), e no Mercado Municipal Central (MORI, 2005). Nos comércios da Liberdade, pode-se observar que não são apenas os japoneses e seus descendentes que representam seus consumidores. A valorização da cultura japonesa atinge muitos brasileiros. A clientela, de muitos desses locais, é constituída por paulistanos de múltiplas procedências adeptos de uma alimentação mais saudável (RIBEIRO, 2006).

De fato, a cozinha japonesa é diferenciada em seu preparo, seus sabores e sua apresentação. O Japão é um país cercado de mar e cortado por rios; por isso, tem, em seus pratos, a forte presença de pescados. No cotidiano, utilizam-se muitos peixes secos. Os legumes são talhados em pequenos formatos e preparados cozidos ou em conservas. $\mathrm{O}$ arroz é o elemento básico da alimentação e muito importante também, tanto que, na Idade Média, era utilizado como moeda de pagamento de impostos. $\mathrm{O}$ molho shoyu e a pasta de soja (missô) dão um sabor característico à cozinha de todo o país (RIBEIRO, 2006).

Os rótulos têm o papel principal de informar aos consumidores sobre o produto a que se dirigem; por isso, as informações contidas, nos rótulos, devem ser claras e poderem ser utilizadas para orientar a escolha adequada de alimentos (CÂMARA; MARINHO; GUILAM, 2008).

A importância da rotulagem nutricional dos alimentos para a promoção da alimentação saudável é destacada em grande parte dos estudos e pesquisas que envolvem a área da nutrição e sua relação com estratégias para a redução do risco de doenças crônicas (BRASIL, 2005).

De acordo com dados levantados junto à população que consulta o serviço DisqueSaúde, no Ministério da Saúde, aproximadamente, $70 \%$ das pessoas consultam os rótulos dos alimentos no momento da compra, no entanto, mais da metade não compreende, adequadamente, o significado das informações (FERREIRA; LANFERMARQUEZ, 2007).

No Brasil, a Agência de Vigilância Sanitária - ANVISA, ligada ao Ministério da Saúde, é o órgão responsável pela regulação da rotulagem de alimentos que estabelece as informações que um rótulo deve conter, visando à garantia de qualidade do produto e à saúde do consumidor. Também, fiscaliza a produção e comer-cialização de alimentos (BRASIL. ANVISA, 2003).

De acordo com o que já foi exposto, e, uma vez que a culinária japonesa considerada saudável, e, atualmente, está muito presente nos hábitos alimentares dos brasileiros, este estudo tem como objetivo avaliar os conteúdos da informação nutricional apresentados nos rótulos de alimentos da culinária japonesa, disponíveis em estabelecimentos comerciais de um bairro oriental de São Paulo, de acordo com as resoluções da ANVISA RDC n 39; RDC no 40 e RDC no 360 .

\section{MATERIAIS E MÉTODOS}

Foram apontados, intencionalmente, 4 (quatro) alimentos da culinária japonesa, o tikuwa, uma pasta de peixe; o manju, um pão doce recheado, geralmente, com doce de feijão; tofu, preparado com leite de soja, 
e o missô, uma pasta fermentada de feijão de soja, vendidos em estabelecimentos comerciais em um bairro oriental de São Paulo, SP. Totalizaram 6 (seis) amostras, o tikuwa e o tofu soft foram adquiridos de duas marcas diferentes, e do manju e do missô foi encontrada apenas uma marca de cada.

Essas amostras de conveniência foram escolhidas por fazerem parte de uma tabela de composição de alimentos específicos da culinária japonesa, desenvolvida por pesquisadores da Universidade de São Paulo, e por se acreditar que não teria grandes variações quanto à composição nutricional.

A coleta de dados e das amostras de alimentos realizou-se no mês de novembro de 2009, em estabelecimentos comerciais, em um bairro oriental de São Paulo.

O cálculo da composição química dos alimentos estudados foi realizado de forma indireta, por meio de tabela de composição de alimentos, organizada para auxiliar a avaliação de consumo alimentar de indivíduos de etnia japonesa residentes no Brasil (TOMITA; CARDOSO, 2002).

A metodologia utilizada pelos pesquisadores da Universidade de São Paulo, na confecção da tabela de composição de alimentos, é apresentada a seguir: a análise química foi realizada de acordo com as Normas Analíticas do Instituto Adolfo Lutz (1985). As análises foram realizadas em triplicata.

A adequação da rotulagem dos alimentos estudados foi verificada de acordo com as recomendações das legislações para rotulagem de alimentos no Brasil, de acordo com as resoluções da ANVISA RDC no 39 (BRASIL, 2001a); RDC ํo 40 (BRASIL, 2001b) e RDC no 360 (BRASIL, 2003).

Foram analisados os seguintes dados da Informação Nutricional: Valor Energético, Carboidratos, Proteínas e Gorduras Totais, por constarem na tabela nutricional, os dados de Sódio e Cinzas foram adicionados somente para ilustrar, pois não foi possível compará-los, uma vez que as cinzas encerram, também, outros minerais.

Os dados foram analisados utilizandose o Coeficiente de Variação (C. V.), que é uma medida relativa de dispersão, calculado pela seguinte fórmula (MONTGOMERY, 2001):

$$
\text { C. V. }=\frac{\text { Desvio padrão }}{\text { Média }} \times 100
$$

\section{RESULTADOS E DISCUSSÃO}

Foram analisados 4 alimentos da culinária japonesa: tikuwa, manju, tofu e missô, obtidos em estabelecimentos comerciais que vendem, principalmente, produtos orientais. No total, foram 6 amostras, 2 amostras de tikuwa, das marcas $A$ e $B$ (Tabela 1), 1 amostra de manju (Tabela 2), 2 amostras de tofu, das marcas A e B (Tabela 3), e 1 amostra de missô (Tabela 4).

A Resolução RDC no 360 preconiza uma tolerância de $20 \%$ a menos ou a mais com relação aos valores de nutrientes declarados no rótulo.

$\mathrm{Na}$ análise dos rótulos de alimentos, realizada neste estudo, quando se compararam as informações nutricionais com a tabela desenvolvida por pesquisadores da Universidade de São Paulo, pode-se verificar: 
Tabela 1 - Comparação entre informação nutricional do Rótulo de Tikuwa, das marcas A e B, e a obtida na tabela de composição de alimentos

\begin{tabular}{ccccc}
\hline $\begin{array}{c}\text { Informação Nutricional em } \\
\mathbf{1 0 0 g}\end{array}$ & $\begin{array}{c}\text { Tikuwa } \\
\text { (marca A) }\end{array}$ & $\begin{array}{c}\text { Tikuwa } \\
\text { (marca B) }\end{array}$ & $\begin{array}{c}\text { Tabela de composição } \\
\text { de alimentos }\end{array}$ & C.V. (\%) \\
\hline Valor Energético (Kcal) & 140 & 600 & 78,2 & 104,5 \\
Carboidratos (g) & 14 & 60 & 13,8 & 157,5 \\
Proteínas (g) & 12 & 60 & 5,7 & 93,6 \\
Gorduras Totais (g) & 4 & 0 & 0,1 & 136,3 \\
Sódio (mg) & 800 & 750 & - & 3,2 \\
Cinzas (g) & - & - & 1,6 & - \\
\hline
\end{tabular}

O coeficiente de variação apresentouse elevado entre os macronutrientes e o valor energético, bem superior a $20 \%$, como preconiza a legislação (BRASIL, 2003).

O tikuwa da marca $B$ foi o produto que obteve maiores variações, em que se encontram diferenças de $667,26 \%$ no valor energético, 334,78\%, nos carboidratos, $952,63 \%$, nas proteínas, sendo que as gorduras totais estavam dentro das especificações da legislação.

O tikuwa da marca $A$ teve menores variações, porém ainda fora das especificações da legislação, que é de tolerância de $\pm 20 \%$. As diferenças foram de $79,03 \%$, no valor energético, $110,53 \%$, nas proteínas e a maior variação foi verificada nas gorduras totais desse produto, que foi de $3.900 \%$, os carboidratos estavam de acordo com a legislação.

De acordo com o resultado de cinzas, da tabela de composição de alimentos, para o Tikuwa, apresentados na Tabela 1, o sódio compõe cerca de $50 \%$ dos minerais, mostrando-se um produto com alto teor de sódio, tanto na marca A como na marca B, cujos valores são bem aproximados entre as duas marcas - coeficiente de variação de $3,2 \%$.

\section{Tabela 2 - Comparação entre informação nutricional do Rótulo de Manju e a obtida na tabela de composição de alimentos}

\begin{tabular}{cccc}
\hline $\begin{array}{c}\text { Informação Nutricional em } \\
\mathbf{1 0 0 g}\end{array}$ & $\begin{array}{c}\text { Manju } \\
\text { (rótulo) }\end{array}$ & $\begin{array}{c}\text { Tabela de Composição de } \\
\text { Alimentos }\end{array}$ & C.V. (\%) \\
\hline Valor Energético (kcal) & 227,5 & 175,6 & 18,2 \\
Carboidratos $(\mathrm{g})$ & 50 & 35,2 & 17,4 \\
Proteínas $(\mathrm{g})$ & 3,25 & 4 & 10,3 \\
Gorduras Totais $(\mathrm{g})$ & 1,7 & 2,1 & 10,5 \\
Sódio $(\mathrm{mg})$ & 74 & - & - \\
Cinzas $(\mathrm{g})$ & - & 0,4 & - \\
\hline
\end{tabular}

O manju analisado foi o que teve menores variações, o coeficiente de variação de todos os elementos calculados estava dentro da tolerância de $20 \%$, preconizada pela legislação.
De acordo com o resultado de cinzas, da tabela de composição de alimentos, para o manju, apresentado na Tabela 2, o sódio compõe cerca de $20 \%$ dos minerais. 
Tabela 3 - Comparação entre informação nutricional do Rótulo de Tofu Soft, das marcas A e B, e a obtida na tabela de composição de alimentos

\begin{tabular}{ccccc}
\hline $\begin{array}{c}\text { Informação Nutricional em } \\
\mathbf{1 0 0 g}\end{array}$ & $\begin{array}{c}\text { Tofu soft } \\
\text { (marca A) }\end{array}$ & $\begin{array}{c}\text { Tofu soft } \\
\text { (marca B) }\end{array}$ & $\begin{array}{c}\text { Tabela de Composição } \\
\text { de Alimentos }\end{array}$ & C.V. (\%) \\
\hline Valor Energético (kcal) & 75 & 146,7 & 45,5 & 58,4 \\
Carboidratos (g) & 2,3 & 6,7 & 3,1 & 18,5 \\
Proteínas (g) & 10 & 13,3 & 5,5 & 33,3 \\
Gorduras Totais (g) & 5 & 10 & 1,3 & 65,6 \\
Sódio (mg) & 2,5 & 26,7 & - & 82,9 \\
Cinzas (g) & - & - & 0,2 & - \\
\hline
\end{tabular}

O coeficiente de variação para carboidratos apresentou-se abaixo de $20 \%$, tolerância aceita pela legislação. Os demais macronutrientes e valor energético não obedeceram a legislação.

O tofu soft da marca A teve menores variações em relação ao da marca $B$, porém ambos estavam fora dos padrões estabelecidos pela legislação. O tofu soft da marca $A$ teve a diferença de $64,84 \%$ para energia, para carboidratos de $-25,81 \%$, proteínas de $81,82 \%$, e gorduras totais de $284,62 \%$.
O tofu soft da marca B teve diferenças ainda maiores, com diferença de $222,42 \%$ no valor energético, 116,13\%, nos carboidratos, $141,82 \%$, nas proteínas, e $669,23 \%$, nas gorduras totais.

De acordo com o resultado de cinzas da tabela de composição de alimentos para o tofu, apresentados na Tabela 3, o sódio compõe cerca de $1 \%$ dos minerais para a marca $A$ e $10 \%$ para a marca $B$, demonstrando um teor muito variado entre as duas marcas - coeficiente de variação maior que $80 \%$.

Tabela 4 - Comparação entre informação nutricional do Rótulo do Missô, e a obtida na tabela de composição de alimentos

\begin{tabular}{cccc}
\hline $\begin{array}{c}\text { Informação Nutricional em } \\
\mathbf{1 0 0 g}\end{array}$ & $\begin{array}{c}\text { Missô } \\
\text { (rótulo) }\end{array}$ & $\begin{array}{c}\text { Tabela de Composição de } \\
\text { Alimentos }\end{array}$ & C.V. (\%) \\
\hline Valor Energético (kcal) & 175 & 108,1 & 33,4 \\
Carboidratos $(\mathrm{g})$ & 13 & 5 & 44,4 \\
Proteínas $(\mathrm{g})$ & 13 & 11 & 8,5 \\
Gorduras Totais $(\mathrm{g})$ & 8 & 4,9 & 24,1 \\
Sódio $(\mathrm{mg})$ & 928 & - & - \\
Cinzas $(\mathrm{g})$ & - & 8,7 & - \\
\hline
\end{tabular}

De acordo com o coeficiente de variação, o missô também estava fora da tolerância estabelecida pela legislação, exceto para proteínas.

De acordo com o resultado de cinzas da tabela de composição de alimentos para o missô, apresentado na Tabela 4, o sódio compõe cerca de $10 \%$ dos minerais.

De acordo com a análise realizada na informação nutricional dos produtos, 100\% dos rótulos apresentaram não conformidade de acordo com a legislação brasileira 
vigente.

Em relação à resolução da ANVISA RDC $\mathrm{n}$ - 39 , todos os rótulos estavam conformes, pois apresentaram medidas caseiras dentro da gramatura adequada aos produtos.

De acordo com RDC no 40, da ANVISA, na rotulagem o fabricante deverá apresentar uma tabela com a composição nutricional e a contribuição de cada nutriente, com base numa porção individual de referência, para a dieta diária do consumidor. Esse quesito foi atendido por todos os rótulos de produtos analisados.

Com base nas resoluções da ANVISA, RDC n 39 e n 40 , não foram encontradas não conformidades, porém, o objetivo dessas legislações é 0 de fornecer informações que permitam ao consumidor a escolha adequada dos alimentos que irão compor sua dieta. Visto que essas porções e proporções de nutrientes foram baseadas em uma informação nutricional totalmente equivocada, não se pode afirmar que essas informações possam auxiliar o consumidor em escolhas nutricionais adequadas.

Em um estudo desenvolvido por Lobanco (2007), que analisou o rótulo de 151 produtos industrializados, sendo 56 salgados e 95 doces, o intervalo de condenação, para proteínas, variou de 0 a $50 \%$, para carboidratos variou de 0 a $40 \%$, e a maior variação ocorreu para gorduras totais, entre 0 e $85 \%$. No caso dos alimentos analisados no presente estudo, o intervalo de variação foi ainda maior, ou seja, de 10 a 93\% para proteínas, de 17 a 157\% para carboidratos e de 10 a $136 \%$ para gorduras totais, que, por se tratar de nutrientes energéticos, acarretam grande variação ao valor calórico dos produtos.
Em outros estudos realizados, comparando-se rótulos a tabelas de composição de alimentos (PHILIPPI; LATERZA; LORENZANO, 1995; MATTA; HENRIQUES; SILVA, 2006) também foram encontrados resultados que divergem da legislação.

A culinária japonesa é considerada saudável e, atualmente, está muito presente nos hábitos alimentares brasileiros (YASSUNAGA; PHILIPPI; KITAGAWA, 2006); dessa forma, a informação nutricional desses produtos merece maior cuidado, pois cada vez mais consumidores podem depender das informações contidas nesses rótulos.

Então, outros estudos devem ser realizados, devido à importância que os alimentos da culinária japonesa têm na atualidade, visto 0 grande número de restaurantes, comércios alimentícios que existem, principalmente, na cidade de São Paulo, e muitas pessoas podem consumir esses tipos alimentos considerados saudáveis.

Os alimentos de marcas diferentes apresentam variações quanto aos temperos utilizados, quantidades de cada ingrediente, tipos de ingredientes, entre outros aspectos. Todas essas variações podem ser uma justificativa para as diferenças encontradas neste estudo. Porém, na maioria dos alimentos analisados, as diferenças entre a composição nutricional dos rótulos e a tabela eram elevadas, não tendo, assim, uma explicação muito certa quanto a essas variações.

Sabe-se que a melhor forma de analisar a composição química e nutricional dos alimentos é realizada por métodos analíticos, efetuados em laboratório de bromatologia, pois os alimentos apresentam 
variações (SAUERBRONN, 2003). Dessa forma, recomenda-se que outros estudos sejam realizados, de forma direta, com alimentos da culinária japonesa, levando-se em consideração a indicação desses resultados.

É necessário que as informações nutricionais contidas nos rótulos de produtos apresentem valores que expressem a realidade e sejam plenamente compreendidos pela população (LOBANCO, 2007).

A legislação brasileira vigente acerca da rotulagem de produtos alimentícios é satisfatória e pode ser comparada às de países de primeiro mundo, em quase todos os aspectos (CELESTE, 2001), porém sua implementação e a fiscalização são incipientes, fazendo com que as informações nutricionais não sejam declaradas de forma precisa (MATTA; HENRIQUES; SILVA, 2006). No caso dos rótulos estudados, se estiverem influenciando os consumidores, em suas escolhas, podem se tornar um problema na promoção da Saúde Pública.

Há necessidade de muitos ensaios na área de recomendações nutricionais e composição dos alimentos, além do respaldo de uma opinião pública bem informada, para o efetivo controle da rotulagem de alimentos.

\section{CONCLUSÃO}

Pode-se concluir que há uma disparidade, muito grande, entre o que está no rótulo e o encontrado nas tabelas de composição de alimento.

De acordo com os resultados dessa pesquisa e a metodologia utilizada, os rótulos analisados não estavam conformes com a Resolução da ANVISA RSC n 360. Em relação às resoluções da ANVISA, RDC no 39 e $n^{\circ} 40$, não foram encontradas não conformidades, porém as porções e proporções de nutrientes estudadas foram baseadas em informações nutricionais não conformes, não fazendo com que esses dados possam ser fidedignos para a orientação do consumidor.

A rotulagem nutricional tem por finalidade informar ao consumidor quanto à qualidade e quantidade de nutrientes dos constituintes nutricionais dos alimentos, garantindo, assim, escolhas apropriadas e adequadas; por isso, é muito importante a fidelidade das informações. Os dados apresentados, neste estudo, indicam que os rótulos dos produtos analisados não podem cumprir tal função, uma vez que, em todos, foram encontradas não conformidades.

\section{REFERÊNCIAS}

BRASIL. ANVISA - Agência Nacional de Vigilância Sanitária. Resolução n 39 de 21de março de 2001. Aprova a Tabela de Valores de Referência para Porções de Alimentos Embalados para Fins de Rotulagem Nutricional. In: Diário Oficial ( $\mathrm{Da}$ Republica Federativa do Brasi), Brasília, 21 de março de 2001a.

Resolução no 40 de 21 de março de 2001. Aprova O Regulamento Técnico para Rotulagem Nutricional Obrigatória de Alimentos e Bebidas Embalados. In. Diário Oficial (Da Republica Federativa do Brasil), Brasília, 21 de março de 2001b.

- Resolução - RDC no 360 de 23/12/03 - Regulamento Técnico Sobre Rotulagem Nutricional de Alimentos, 2003. Disponível

em: <http://www.anvisa.gov.br/legis/resol/2003/rd 
c/360_03rdc.htm>. Acesso em: 12 fev. 2010.

BRASIL. Ministério da Saúde. Rotulagem

Nutricional Obrigatória. Manual de Orientação às Indústrias de Alimentos. Brasília, DF, 2005. Disponível em: <http://www.anvisa.gov.br/rotulo/manual_ind ustria.pdf>. Acesso em: 14 mar. 2010.

CAMARA, M. C. C.; MARINHO, C. L. C.; GUILAM, M. C. R. Análise crítica da rotulagem de alimentos diet e light no Brasil. Cad. saúde colet., (Rio J.), n. 1, v. 16, p. 3552, 2008.

CELESTE, R. K. Análise comparativa da legislação sobre rótulo alimentício do Brasil, Mercosul, Reino Unido e União Européia. Rev. Saúde Pública, São Paulo, 2001. Disponível em: <http://www.scielo.br/pdf/rsp/v35n3/5004.pdf . Acesso em: 30 abr. 2010.

FERREIRA. A. B, LANFER-MARQUEZ, U. M. Legislação brasileira referente à rotulagem nutricional de alimentos. Rev. Nutr., Campinas, n. 20, v. 1, p. 83-93, jan./fev., 2007.

NORMAS ANALÍTICAS DO INSTITUTO ADOLFO LUTZ. (São Paulo). Métodos químicos e físicos para análise de alimentos. 3 ed. São Paulo: Instituto Adolfo Lutz, 1985. Disponível em: $<$ http://www.ial.sp.gov.br/index.php?option=c om_remository\&ltemid=7\&func=select\&order by $=1 \&$ Itemid=7 >. Acesso em: 30 abr. 2010.

LOBANCO, C. M. Rotulagem nutricional de alimentos salgados e doces consumidos por crianças e adolescentes. 2007. Dissertação (Pós-graduação em Saúde Pública) Universidade de São Paulo. São Paulo, 2007. Disponível em: <http://pandora.cisc.usp.br/teses/disponiveis /6/6133/tde-12052008140337/publico/CassiaLobanco.pdf>.
Acesso em: 30 abr. 2010.

MATTA, I. E. A.; HENRIQUES, P.; SILVA, Y. Adequação à legislação vigente da rotulagem de alimentos diet $e$ light comercializados no Rio de Janeiro, RJ. Hig. aliment., v.20, n. 147, p.97-103, dez. 2006.

MONTGOMERY, D. C. Introduction to statistical quality control. New York. 4th Edition, Wiley, 2001.

MORI, K. Burajiru no Nihon-Ryôri to Nihon no Burajiru Ryôri (Culinária Japonesa no Brasil / Culinária brasileira no Japão). Revista Especializada da Cultura Culinária Vesta, Tokyo, v. 58, p. 73, 2005.

PHILIPPI, S. T., LATERZA, A. R., LORENZANO, C. Avaliação sobre valor nutritivo em rótulos e/ou embalagens de alimentos infantis: iogurte, queijo "petit suisse" e bebida láctea. Rev. Hig. Alimentar, 1995, v. 9, p. 38.

RIBEIRO, C. M. A. Gastronomia, Interação cultural e Turismo: estudo sobre a dispersão culinária nipônica na Cidade de São Paulo 100 anos da imigração japonesa no Brasil. 2006. Dissertação (Mestrado em Turismo) Universidade de Caxias do Sul. Caxias do Sul, 2006. Disponível em: <http://www.ucs.br/ucs/tplSemMenus/posgra duacao/strictosens

u/turismo/seminarios/seminario_4/arquivos_ 4_seminario/GT03-5.pdf>. Acesso em: 12 fev. 2010.

SAUERBRONN, A. L. A. Análise laboratorial da composição de alimentos processados como contribuição ao estudo da rotulagem nutricional obrigatória de alimentos e bebidas embalados no Brasil. 2003. Dissertação (Mestrado em Vigilância Sanitária). Instituto Nacional de Controle de Qualidade em Saúde, Fundação Oswaldo Cruz, Rio de Janeiro, 2003. Disponível em: 
<http://bvssp.cict.fiocruz.br/lildbi/docsonline/ YASSUNAGA, E.; PHILIPPI, S. $\quad$ T.; get.php?id=214 >. Acesso em: 30 abr. 2010. KITAGAWA, M. M. Culinária japonesa: valor TOMITA, L. Y.; CARDOSO, M. A. Relação de medidas caseiras, composição química $e$ receitas de alimentos nipo-brasileiros. 2. ed. São Paulo: Metha, 2002. nutritivo de alimentos consumidos no Brasil. 2006. XIX Congresso Brasilero de Nutrição, $2006 . \quad$ Disponível em: $<$ http://www.usp.br/siicusp/Resumos/14Siicu sp/673.pdf>. Acesso em: 30 abr. 2010. 